\title{
Comparação entre variáveis microclimáticas de local aberto e florestal em um bioma da Mata Atlântica, sul do Brasil
}

\author{
Comparison between microclimatic variables in open and forest sites at Mata \\ Atlântica biome, southern Brazil
}

\author{
Rafael GotardoI, Adilson Pinheiro' ${ }^{\mathrm{II}}$, Gustavo Antônio Piazza ${ }^{\mathrm{III}}$, Vander Kaufmann ${ }^{\mathrm{IV}}$, \\ Edson Torres ${ }^{\mathrm{V}}$
}

\begin{abstract}
Resumo
Na região subtropical do Brasil, o ambiente é naturalmente caracterizado pelo clima quente e úmido. Essas condições são fatores preponderantes para a ocorrência da formação florestal na região, o bioma Mata Atlântica. Associa-se que qualquer condição diferente daquela que não seja natural, pode receber de forma diferenciada a condição meteorológica local. Supõe-se que florestas ajam como reguladoras, atenuando os índices meteorológicos e microclimáticos. Este estudo comparou uma série temporal de três anos de registro de duas estações meteorológicas, uma em área aberta de pastagem e outra abaixo do dossel de um fragmento florestal de floresta ombrófila densa (Mata Atlântica) em estágio avançado de regeneração. Foram monitoradas a precipitação, a umidade relativa do ar, a radiação global, a temperatura do ar, a velocidade do vento e a temperatura do solo. A evapotranspiração potencial diária foi estimada pela equação de Penman-Monteith (PM-FAO56) para as duas condições. A área florestal apresentou condições meteorológicas diferenciadas em relação à área aberta (pastagem). Por exemplo, o dossel florestal reteve $41,2 \%$ da precipitação anual (menor drenagem superficial), a temperatura média diária do ar foi reduzida em $9,5 \%$ no ano, assim como a velocidade média do vento, em $87,6 \%$, e a média da radiação global, em $88,1 \%$. A evapotranspiração potencial foi $89,1 \%$ superior na pastagem. Valor comprovado pela média anual da umidade do ar, que foi de 7,6\% maior no ambiente florestal. O comportamento diário das variáveis mostrou maiores valores na pastagem e por volta das $15 \mathrm{~h}$, e mais baixos na floresta no período noturno. Exceto para a umidade relativa do ar que foi inverso. Ou seja, na pastagem ocorrem perdas maiores de água para a atmosfera. $\mathrm{O}$ ambiente florestal, por outro lado, retém mais água, formando um "microclima" em seu interior.
\end{abstract}

Palavras-chave: Floresta; Monitoramento hidrometeorológico; Microclima

\begin{abstract}
In the subtropical region of Brazil, the environment is naturally characterized by the hot and humid climate. These conditions are preponderant factors for the occurrence of forest formation, the Atlantic Forest biome. Any non-natural environment can receive negatively the local meteorological condition. Forests act as regulators mitigating the meteorological and microclimatic indices. Three-year data of two meteorological stations were used, one in an open pasture area and one under the canopy of a forest fragment of the dense Ombrophilous forest (Mata Atlântica) in advanced stage of regeneration. Precipitation, relative air humidity, global radiation, air temperature, wind speed and soil temperature were monitored. Potential daily evapotranspiration was estimated by the Penman-Monteith equation (PM-FAO56) for both conditions. The forest area presented different meteorological conditions when compared to the open area (pasture). For example, forest canopy retained $41.2 \%$ of annual precipitation (lower surface drainage), the average daily air temperature was reduced by $9.5 \%$, as well as the average

Engenheiro Agrônomo, MSc., Programa de Pós-Graduação em Engenharia Ambiental, Fundação Universidade de Blumenau, Campus II, Rua São Paulo, 3250 - Itoupava Seca, CEP 89030-000, Blumenau (SC), Brasil. rafael.piratuba@yahoo.com.br (ORCID: 0000-0003-1316-5181)

Engenheiro Civil, Dr., Professor do Programa de Pós-Graduação em Engenharia Ambiental, Fundação Universidade de Blumenau, Campus II, Rua São Paulo, 3250 - Itoupava Seca, CEP 89030-000, Blumenau (SC), Brasil. pinheiro2907@gmail.com (ORCID: 0000-0001-8546-0046)

III Engenheiro Ambiental, MSc., Programa de Pós-Graduação em Engenharia Ambiental, Fundação Universidade de Blumenau, Campus II, Rua São Paulo, 3250 - Itoupava Seca, CEP 89030-000, Blumenau (SC), Brasil. gustavoapiazza@gmail.com (ORCID: 0000-0001-8407-9606)

Biólogo, Dr., Professor do Programa de Pós-Graduação em Engenharia Ambiental, Fundação Universidade de Blumenau, Campus II, Rua São Paulo, 3250 - Itoupava Seca, CEP 89030-000, Blumenau (SC), Brasil. vanderkaumann@gmail.com (ORCID: 0000-0002-2971-5128)

Químico, MSc., Programa de Pós-Graduação em Engenharia Ambiental, Fundação Universidade de Blumenau, Campus II, Rua São Paulo, 3250 Itoupava Seca, CEP 89030-000, Blumenau (SC), Brasil. ettotorres@gmail.com (ORCID: 0000-0001-9535-516)
\end{abstract}


wind speed by $87.6 \%$, and mean radiation by $88.1 \%$. Potential evapotranspiration was $89.1 \%$ higher in pasture. This value is corroborated by the annual average of air humidity which was $7.6 \%$ higher in the forest. The daily behavior of meteorological variables showed higher values in the pasture and around $15 \mathrm{~h}$, and lower in the forest at night. Except for the relative humidity that was the inverse. In pasture there are larger losses of water to the atmosphere. The forest environment, on the other hand, retains more water, forming a "microclimate" inside the forest canopy.

Keywords: Forest; Hydrometeorological monitoring; Microclimate

\section{Introdução}

Ecossistemas florestais são os mecanismos de retroalimentação entre a interface soloatmosfera (ARTAXO et al., 2014). A substituição da cobertura vegetal natural para outros usos influencia diretamente estes processos. Os impactos são percebidos nas variáveis que compõem o ciclo hidrológico. Ambientes florestais são reguladores do clima, já que a evaporação gerada por elas pode produzir a precipitação (MAKARIEVA; GORSHKOV; LI, 2013). Na Mata Atlântica, microclimas são formados no perfil solo-dossel, no sentido de fornecer condições habitáveis para milhares de espécies animais e vegetais. Os microclimas foram historicamente relatados na literatura em 1927 na Alemanha por Rudolf Geiger, tendo como principais resultados a diferença nas condições do solo quando comparadas com solos de áreas não vegetadas. Desde 1927 até a presente data, outros estudos foram realizados no sentido de ampliar o conhecimento científico no tema, como Ashcroft e Gollan (2012) e Hardwick et al. (2015), que relatam a importância do microclima sobre processos ecológicos, no ciclo hidrológico e na composição atmosférica.

A Mata Atlântica é uma formação florestal de extrema importância local, regional e até global, devido à biodiversidade de espécies animais e vegetais. Em nível nacional é a segunda de maior biodiversidade, perdendo apenas para a floresta Amazônica. Em Santa Catarina, a Mata Atlântica é o bioma florestal dominante. Atualmente, sua cobertura se encontra fragmentada devido à expansão agrícola e à atividade exploratória. De acordo com Salemi et al. (2012), Almeida (2016) entre outros, no Brasil, a Mata Atlântica é o bioma mais afetado em relação à fragmentação florestal, em virtude da exploração madeireira, da expansão agrícola, pecuária e silvicultura. No país restam 12,5\% da área de Mata Atlântica original e em Santa Catarina, os resultados são um pouco mais conservadores. De acordo com inventário florístico e florestal de Santa Catarina (IFFSC) restam em torno de $28 \%$ da cobertura original da Mata Atlântica (VIBRANS et al., 2013).

Em relação à escala, o clima pode ser dividido em: macroclima, mesoclima e microclima. O macroclima é atribuído a fenômenos de escala global e regional (ex. regiões hidrográficas). O mesoclima trata da dinâmica em escalas locais (ex. município) e o microclima em uma área específica (ex. uso do solo e cobertura da terra). As principais variáveis que compõem o clima são: temperatura do ar, umidade relativa, pressão atmosférica, radiação global e velocidade do vento (MENDONÇA; DANNI-OLIVEIRA, 2007). No contexto de microclima, Baker et al. (2014) encontraram menores variações no interior de uma floresta para as variáveis meteorológicas analisadas quando comparados com áreas abertas, em virtude de a cobertura vegetal proporcionar um efeito regulador. No entanto, as alterações antrópicas são promotoras de distúrbios que afetam o comportamento do microclima (HARDWICK et al., 2015). Estudos realizados no bioma Mata Atlântica até o momento são limitados a poucas variáveis climáticas, como o estudo de Santos et al. (2012) que abordou somente temperatura do solo e a radiação, com um período restrito de dados, como Silva et al. (2016) que utilizaram apenas dois meses de dados de temperatura do solo, e em áreas específicas, como Carneiro et al. (2014) que estudaram a temperatura do solo em uma clareira da Mata Atlântica. Ou seja, a maioria destes estudos são restritos, não promovendo a comparação dos resultados e limitando a avaliação microclimática para os diferentes ambientes.

Apesar da importância deste tema na região subtropical, poucos estudos são encontrados na literatura, sendo a maioria na floresta Amazônica e nas regiões temperadas, onde o financiamento por estudos de monitoramento florestal já está consolidado. No bioma Mata Atlântica, estas informações estão restritas a estudos simplificados (como utilização de 
variáveis independentes) e com uma série de dados relativamente curta, como os estudos sobre interceptação e precipitação efetiva de Alves et al. (2007) e Ávila et al. (2014). No intuito de avançar cientificamente e contribuir no entendimento do comportamento microclimático do bioma Mata Atlântica, este estudo comparou a dinâmica temporal de sete variáveis meteorológicas em duas condições distintas de microclima; uma aberta e outra abaixo do dossel de uma área coberta por floresta ombrófila densa, no sul do Brasil.

\section{Material e métodos}

O presente estudo foi desenvolvido na bacia hidrográfica do ribeirão Concórdia, uma bacia de 30,67 $\mathrm{km}^{2}$ localizada no município de Lontras, estado de Santa Catarina, sul do Brasil (27¹1'17,0” S e 4929’40,1” O) (Figura 1).

A precipitação média anual na região é de aproximadamente $1.657 \mathrm{~mm}$, com mínimas de $1.110 \mathrm{~mm}$ e máximas de $2.701 \mathrm{~mm}$ (GOTARDO et al., 2018). O clima é mesotérmico úmido, com temperaturas variando de $15 \mathrm{a} 35^{\circ} \mathrm{C}$. O relevo é parcialmente acidentado com escarpas montanhosas e encostas íngremes, declividade média de 5\% e variação na elevação entre 300 a $900 \mathrm{~m}$.

Figura 1 - Localização do local de estudo e dados meteorológicos utilizados (2012-2015). Cada local está equipado com uma estação meteorológica, uma em floresta e a outra em área aberta.

Figure 1 - Location of the study site where meteorological data used in this study was recorded (2012-2015). Each site is equipped with a meteorological station, one in a forest plot and the other one in an open-area plot.

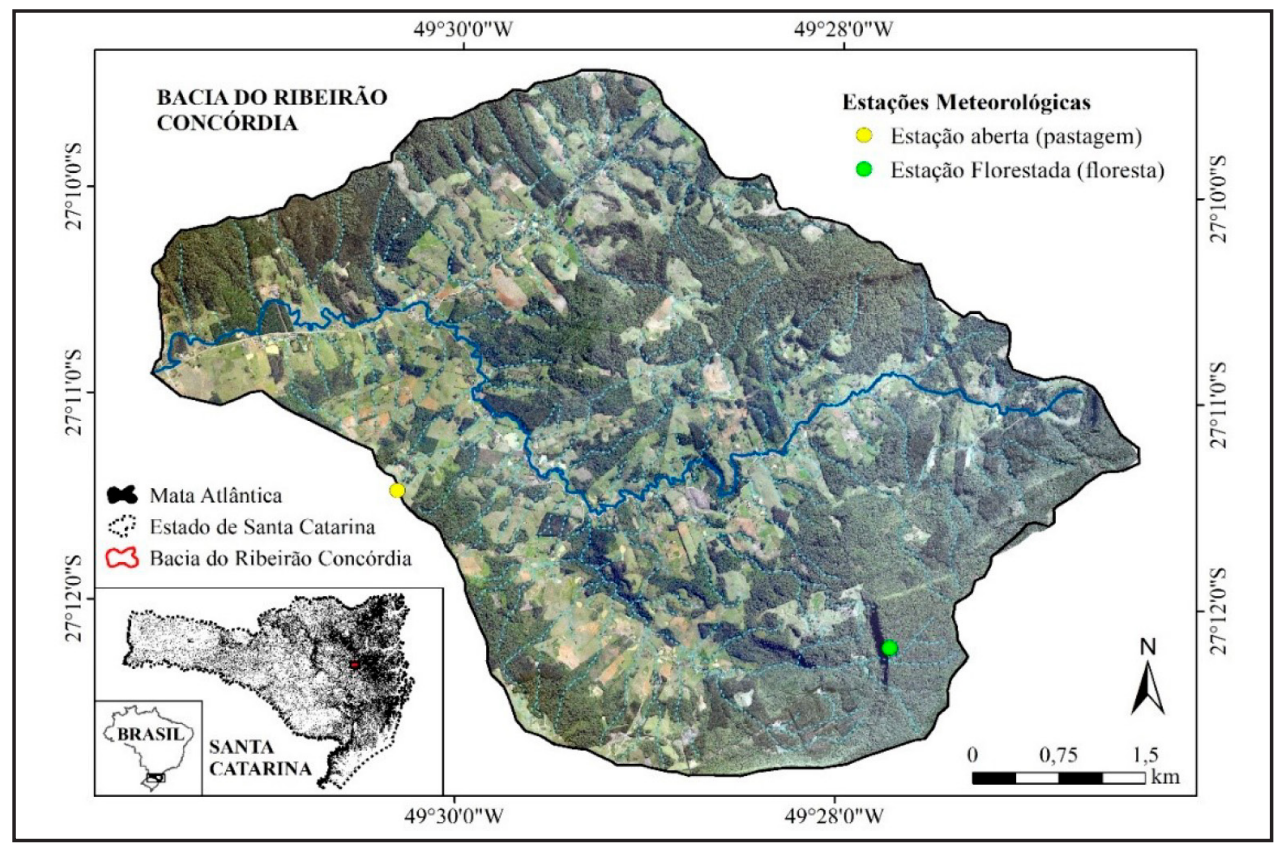

Fonte: Autores (2019)

A coleta de dados foi realizada por duas estações meteorológicas, uma instalada em ambiente aberto (área coberta por pastagem perene [Paspalum notatum]) e outra abaixo do dossel de um fragmento florestal da floresta ombrófila densa em estágio avançado de regeneração. Um inventário de caraterização simplificado foi realizado no local. As árvores do entorno da estação possuem um diâmetro médio de 79,2 cm, altura média de 15,6 metros, compondo cerca de 5.800 indivíduos por hectare. As principais espécies encontradas no local foram: xaxim (Dicksonia 
sellowiana), xaxim-de-espinho (Cyathea corcovadensis), palmito-juçara (Euterpe edulis), canjerana (Cabralea canjerana), cedro (Cedrella fissilis), tanheiro-branco (Alchornea triplinervia), coqueiro-gerivá (Syagrus romanzoffiana) entre outras, bem como a presença de samambaias, bromélias e orquídeas. A estação se encontra a uma distância de 80 metros da borda do ambiente florestal. A estação meteorológica da pastagem está a 534 metros de altitude e a da floresta a 720 metros. Ambas as estações foram equipadas com pluviógrafo do tipo báscula para determinação da precipitação, termômetro (ar e solo), anemômetro, piranômetro e termo-higrômetro. O período de monitoramento foi de três anos hidrológicos, compreendendo entre março de 2012 a março de 2015.

A estação pastagem foi instalada em 2010 de acordo com os requisitos da Organização Mundial de Meteorologia (2008). A referida estação está equipada com um pluviógrafo de compensação da marca WaterLog ${ }^{\circledR}$, série Waterlog $H$-340, modelo 2-SDI-08, que mede a frequência de movimento da báscula. Os dados de precipitação foram armazenados em datalogger $H O B O$ Pendant ${ }^{\circledR}$ em intervalos de tempo de cinco minutos. Um termo hidrômetro da marca Hygrotransmitter ${ }^{\circledR}$ modelo HD-9008TRR foi usado para o monitoramento da umidade relativa do ar. Para a velocidade do vento foi usado um anemômetro ultrassônico da marca Furuno ${ }^{\circledR}$ modelo $C V-4 F$ instalado a 10 metros de altura. A temperatura do ar foi monitorada por um termômetro de resistência de platina, com faixa de medição entre -40 e $+80^{\circ} \mathrm{C}$, e acurácia de $1,5^{\circ} \mathrm{C}$. Os sensores ficam em um abrigo meteorológico de policarbonato. A radiação solar global foi monitorada por piranômetro da marca EKO Instruments ${ }^{\circledR}$ (modelo MS-601), com seletividade espectral de $1 \%$ entre 0,35 e 1,5 $\mu \mathrm{m}$, sensibilidade de $6,99 \mathrm{mV} . \mathrm{W} . \mathrm{m}^{-2}$ e impedância de $53 \mathrm{ohm}$. Os dados meteorológicos desta estação foram armazenados em um datalogger Campbell Scientific ${ }^{\circledR}$, modelo CR 1000, programado para leituras a cada 15 minutos.

A estação floresta possui um pluvióg rafo automático de báscula sem compensação da marca Davis ${ }^{\circledR}$ modelo $7857 \mathrm{M}$, com datalogger registrador Novus $^{\circledR}$. A velocidade do vento foi monitorada por um anemômetro Sonimometer ${ }^{T M}$. A radiação global foi medida por um piranômetro da marca Kipp e Zonne ${ }^{\circledR}$ modelo CMP3 instalado a 3,0 m de altura, que possui um tempo de resposta de aproximadamente 18 segundos e uma sensibilidade de $10 \mathrm{mV} \cdot \mathrm{W} . \mathrm{m}^{-2}$. A umidade relativa do ar foi monitorada através de um sensor de temperatura e umidade da marca Delta $O H M^{\circledR}$, modelo $H D$-9008-TRR, tendo uma precisão de $\pm 1,5$ até $90 \%$ e de $\pm 2,0 \%$ acima. Os dados meteorológicos foram armazenados em um sistema de aquisição de dados da marca Water $\log ^{\circledR}$ modelo $H-500 X L$, programado para fazer leituras a cada 15 minutos e armazenamento dos dados a cada hora.

A evapotranspiração potencial $(E T p)$ diária foi estimada no interior da floresta e na pastagem pela equação de Penman-Monteith, recomendado pela FAO-56 (AMERICAN SOCIETY OF CIVIL ENGINEERS; ENVIRONMENTAL \& WATER RESOURCES INSTITUTE, 2005).

$$
E T_{p}=\frac{0,408 \times \Delta \times\left(R_{n}-G\right)+\gamma \times \frac{C_{n}}{T+273} \times U_{2} \times\left(e_{s}-e_{a}\right)}{\triangle+\gamma \times\left(1+C_{d} \times U_{2}\right)}
$$

Em que, ETp é a evapotranspiração de referência para culturas $\left(\mathrm{mm} \mathrm{dia}^{-1}\right) ; R_{n}$ é referente ao balanço de radiação líquida na superfície da cultura $\left(\mathrm{MJ} \cdot \mathrm{m}^{-2} \cdot \mathrm{dia}^{-1}\right) ; G$ trata-se da densidade do fluxo de calor na superfície do solo $\left(\mathrm{MJ}^{-\mathrm{m}^{-2}} \cdot \mathrm{dia}^{-1}\right)$; $T$ é temperatura média diária do ar $\left({ }^{\circ} \mathrm{C}\right) ; U_{2}$ é velocidade média diária do vento $\left(\mathrm{m}^{-1} \mathrm{~s}^{-1}\right) ; e_{\mathrm{s}}$ é pressão de saturação de vapor médio diária $(\mathrm{kPa})$; $e_{a}$ é média da pressão atual de saturação de vapor $(\mathrm{kPa}) ; e_{s}$ e $e_{a}$ é deficit de pressão de saturação de vapor $(\mathrm{kPa}) ; \Delta$ é atribuido a inclinação da curva de pressão de vapor de saturação $\left(\mathrm{kPa} .{ }^{\circ} \mathrm{C}^{-1}\right) ; \gamma$ é a constante psicométrica $\left(\mathrm{kPa} .{ }^{\circ} \mathrm{C}^{-1}\right)$; Cn é a constante do numerador para o tipo de cultura de referência e o intervalo de tempo $\left(\mathrm{K} \cdot \mathrm{mm} \cdot \mathrm{s}^{-3} \cdot \mathrm{Mg}^{-1} \cdot \mathrm{dia}^{-1}\right)$; $C d$ é constante do denominador para o tipo de cultura de referência e o intervalo de tempo $\left(\mathrm{s} \cdot \mathrm{m}^{-1}\right)$. O coeficiente 0,408 é o valor inverso do calor latente de vaporização $\left(\lambda=2,45 \mathrm{MJ} \cdot \mathrm{kg}^{-1}\right)$.

$\mathrm{Na}$ equação de Penman-Monteith considerou-se a altitude específica dos locais de monitoramento para a determinação da radiação de dias claros $(R s o)$, bem como a longitude no 
cálculo da radiação no topo da atmosfera $(R a)$. As constantes do numerador $(C d)$ e do denominador $(C n)$ foram: floresta $(C n=1600$ e $C d=0,38)$; pastagem $(C n=900$ e $C d=0,34)$ (AMERICAN SOCIETY OF CIVIL ENGINEERS; ENVIRONMENTAL \& WATER RESOURCES INSTITUTE, 2005). Já para o cálculo da radiação de ondas curtas foi considerado os valores de albedo de 0,11 para a área de floresta (TASUMI; ALLEN; TREZZA, 2008) e de 0,20 para a área de pastagem (VON RANDOW et al., 2004).

A determinação da temperatura do solo foi realizada em cada um dos ambientes com termômetros termopar (tipo cobre/constantan) de resistência Platinum $\left(100 \Omega @ 0^{\circ} \mathrm{C}\right)$. Os termômetros foram instalados a uma profundidade variando de 0 a $10 \mathrm{~cm}$. A capacidade de armazenamento de água pelo dossel vegetativo foi realizada por meio da análise de regressão linear entre os dados diários da precipitação interna e externa. Foi realizada a análise do comportamento diário das variáveis para diferentes horários do dia (3h, 9h, 15h e 21h).

A análise estatística foi executada no software Statistica (Statsoft version 10.0). Para avaliar a normalidade dos dados foi usado o teste de Shapiro-Wilks e pelo $p$ normal comparado estatisticamente pelo teste de Tukey a $5 \%$ de significância. Dados foram analisados em caráter anual, sazonal e diário.

\section{Resultados e discussão}

Diferenças significativas foram encontradas entre as médias anuais (Tabela 1) e sazonais (Figura 2) da estação meteorológica da pastagem para com a estação meteorológica da floresta.

Tabela 1 - Médias anuais da estação meteorológica aberta (pastagem) e florestal (2012-2015).

Table 1 - Annual averages of open (grassland) and the forest weather station (2012-2015).

\begin{tabular}{|c|c|c|c|c|c|c|c|c|}
\hline \multirow{2}{*}{ Variáveis } & \multicolumn{6}{|c|}{ Estações meteorológicas } & \multirow{2}{*}{$\begin{array}{l}\text { Diferença } \\
\text { (valor) }\end{array}$} & \multirow{2}{*}{$\begin{array}{l}\text { Diferença } \\
(\%)\end{array}$} \\
\hline & & rna & & & Externa & & & \\
\hline $\begin{array}{l}\text { Precipitação }(\mathbf{m m} . \\
\text { ano-1) }^{-1}\end{array}$ & $1.343,2$ & \pm & 36,2 & $2.284,1$ & \pm & 64,5 & 940,9 & 41,2 \\
\hline $\begin{array}{l}\text { Umidade relativa do } \\
\text { ar }(\%)\end{array}$ & 95,9 & \pm & 1,3 & 89,1 & \pm & 1,1 & $-6,8$ & $-7,6$ \\
\hline  & $5.785,5$ & \pm & 112,1 & $48.341,3$ & \pm & $1.042,7$ & $42.555,9$ & 88,0 \\
\hline $\begin{array}{l}\text { Temperatura do ar } \\
\left({ }^{\circ} \mathrm{C}\right)\end{array}$ & 16,8 & \pm & 2,8 & 18,5 & \pm & 3,2 & 1,8 & 9,5 \\
\hline $\begin{array}{l}\text { Velocidade do vento } \\
\left(\mathbf{m} . \mathbf{s}^{-1}\right)\end{array}$ & 0,4 & \pm & 0,1 & 3,1 & \pm & 87,5 & 2,7 & 87,6 \\
\hline $\begin{array}{l}\text { Evapotranspiração } \\
\left(\mathbf{m m} \cdot \text { ano }^{-1}\right)\end{array}$ & 192,4 & \pm & 4,0 & $1.764,3$ & \pm & 37,0 & $1.571,9$ & 89,1 \\
\hline $\begin{array}{l}\text { Temperatura do solo } \\
\left({ }^{\circ} \mathrm{C}\right)\end{array}$ & 16,7 & \pm & 2,5 & 19,2 & \pm & 3,6 & 2,5 & 13,0 \\
\hline
\end{tabular}

Os valores anuais foram mais elevados na pastagem, exceto para a umidade relativa do ar. A menor diferença registrada entre as áreas monitoradas foi para a umidade relativa do ar e a maior para a evapotranspiração potencial. A precipitação anual no interior da floresta foi inferior à pastagem, em virtude de a floresta possuir um potencial de interceptação pelo dossel de $41,2 \%$, fazendo com a água fique predisposta para evaporação. O escoamento de tronco foi 
desconsiderado uma vez que muitos autores relatam sobre as dificuldades na quantificação e aos erros que podem ser maiores que a própria taxa de escoamento (CUARTAS et al., 2007). Alves et al. (2007) e Freitas et al. (2013) encontraram valores de 21 e 19\%, respectivamente, para interceptação florestal em áreas da Mata Atlântica. Segundo Moura et al. (2009), a frequência e a intensidade dos eventos de chuvas são responsáveis na dinâmica da interceptação, já que chuvas de baixa intensidade registram maiores taxas de interceptação. $\mathrm{Na}$ dinâmica mensal do período analisado (Figura 2) a precipitação em ambas as estações teve um padrão temporal semelhante, o que indica que a chuva foi homogênea no local estudado.

Figura 2 - Valores diários de precipitação $(\mathrm{mm} / \mathrm{mês})$, umidade relativa do ar $(\%)$, radiação global $\left(\mathrm{MJ} . \mathrm{m}^{2}\right)$, temperatura do $\operatorname{ar}\left({ }^{\circ} \mathrm{C}\right)$, velocidade do vento $\left(\mathrm{m} \cdot \mathrm{s}^{-1}\right)$, evapotranspiração potencial $\left(\mathrm{mm} \cdot \mathrm{dia}^{-1}\right)$ e temperatura do solo $\left({ }^{\circ} \mathrm{C}\right)$ para ambientes estudados $(2012-2015)$.

Figure 2 - Daily values of precipitation ( $\mathrm{mm} / \mathrm{month})$, relative air humidity $(\%)$, global radiation $\left(\mathrm{MJ} . \mathrm{m}^{2}\right)$, air temperature $\left({ }^{\circ} \mathrm{C}\right)$, wind speed $\left(\mathrm{m}^{-1} \mathrm{~s}^{-1}\right)$, potential evapotranspiration $\left(\mathrm{mm}^{\mathrm{day}}{ }^{-1}\right)$ and soil temperature $\left({ }^{\circ} \mathrm{C}\right)$ for the studied environments (2012-2015).



Fonte: Autores (2019) 
A maior precipitação mensal em ambas as estações ocorreu em junho de 2014, com 268,4 $\mathrm{mm}$ para o interior da floresta e de $429,5 \mathrm{~mm}$ para a área aberta (pastagem). Com este resultado foi possível notar o efeito do processo de interceptação do dossel e do sub-bosque, por meio das folhas e caules, reduzindo e retardando o volume de água que chega ao solo. A floresta ombrófila densa possui vários níveis de sub-bosques, com presença de arbustos mais baixos e palmeiras extremamente altas, que utilizam folhas amplas para maximizar a captura da luz solar e consequentemente aumentam o potencial de retenção de captura de água nas folhas. Essa água retida pelas plantas diminui a drenagem superficial responsável por subprocessos de erosão e transporte de sedimentos, típicos na bacia representativa utilizada e na macro bacia do rio ItajaíAçú.

O menor valor de interceptação foi encontrado no mês de março de 2014 (20,36\%) e o maior no mês de novembro de 2012 (58,68\%). Este resultado está relacionado à estação do ano e à dinâmica florestal regional, sendo que no outono (março-junho) é marcado pela queda das folhas de algumas espécies, gerando uma diminuição da captação da água da chuva pelo dossel vegetativo. Na primavera (setembro-dezembro), a floresta inicia o período de brotação e consequentemente aumenta o índice de área foliar, bem como aumenta consigo a área de interceptação das chuvas. Esse processo também foi descrito por Venâncio e Oliveira (2017). A sazonalidade da precipitação mostrou maior ocorrência de chuvas no verão, com máxima de $832,5 \mathrm{~mm}$ na pastagem e $440,1 \mathrm{~mm}$ na floresta, relacionado ao período chuvoso da região. A menor média foi encontrada no período de inverno para a pastagem $(506,4 \mathrm{~mm})$ e na primavera para o interior da floresta $(323,8 \mathrm{~mm})$, relacionado com os fatores já explicados e associados às variações dos índices de área foliar.

A umidade relativa do ar na pastagem foi maior para o inverno $(91,9 \%)$ e menor no verão (85,1\%). A umidade relativa do ar aparentemente não sofreu influência do índice precipitado por estação do ano no ambiente aberto. O interior da floresta apresentou um comportamento semelhante, com valores elevados no inverno $(97,74 \%)$ e baixo no verão $(93,3 \%)$. De acordo com Arruda (2011), as florestas tendem a apresentar maior umidade relativa após o período de rebrota das folhas, em condições de maior temperatura e na estação chuvosa, no qual a maior quantidade de água fica disponível nas folhas, proporcionando a evaporação direta da água das plantas. De acordo com Renaud et al. (2011) geralmente as florestas proporcionam aumento da umidade local, com o efeito sendo particularmente marcado em florestas decíduas durante o período vegetativo.

A umidade relativa do ar no interior da floresta (Figura 3) permaneceu acima dos $90 \%$ durante todo o período, 7,6\% mais úmido que a área de pastagem durante o período de registro. Este resultado também foi observado por Arruda (2011) que também encontrou maiores valores de umidade relativa do ar dentro do dossel das florestas, quando comparado com áreas abertas. A variação diária da umidade relativa foi menor $(23,6 \%)$ na floresta e maior na pastagem $(47,6 \%)$, demonstrando o efeito regulador da floresta. Vale destacar que a parte interna da floresta foi capaz de manter a umidade relativa do ar elevada mesmo nos períodos mais quentes do ano, como o verão. Este resultado mostra que a substituição da cobertura vegetal por áreas de pastagem além dos impactos causados ao solo, também altera a condições microclimáticas locais, ao contrário das áreas de floresta.

$\mathrm{Na}$ área aberta foram determinados os maiores valores de radiação. O período do verão registrou valores máximos de 5.100,12 $\mathrm{MJ} \cdot \mathrm{m}^{-2}$ e o período de inverno com os menores de 3.260,00 $\mathrm{MJ} . \mathrm{m}^{-2}$. No interior da floresta, os valores foram inferiores, sendo o maior registro para a primavera $686,01 \mathrm{MJ} \cdot \mathrm{m}^{-2}$ e o menor de $375,35 \mathrm{MJ} \cdot \mathrm{m}^{-2}$ para o outono (Figura 2). Este resultado é atribuído aos maiores níveis de incidência durante as estações de primavera/verão para as regiões nordeste, centro-oeste e sul. No inverno, menores valores de radiação são justificados pelo aumento da nebulosidade ocorrido no período de outono/inverno (MOOJEN; CAVALCANTE; MEDES, 2012). A radiação solar global apresentou um somatório anual de $48.341,3 \mathrm{MJ} \cdot \mathrm{m}^{-2}$ para a área aberta e de $5.785,5 \mathrm{MJ} . \mathrm{m}^{-2}$ para o interior da floresta, ou seja, $88,0 \%$ da radiação que incide sobre o dossel vegetativo é absorvida, transmitida ou refletida pela vegetação. $\mathrm{Na}$ estação floresta a radiação 
solar também apresentou menor variação diária $( \pm 112,1)$ em relação a estação pastagem $( \pm 1.042,7)$. Este resultado mostra a capacidade de o dossel das árvores atenuar e transmitir a radiação solar global. Vários autores descrevem que menos de $10 \%$ total que atinge o topo das florestas chega a vegetação dos sub-bosques. Para Bonan (2008), a copa das florestas pode bloquear até $95 \%$ da luz visível que chega ao solo. A atenuação da incidência solar pela vegetação também é citada por Mahmoud (2011), que além da redução da radiação relata a redução da temperatura do ar. Os maiores índices de radiação ocorreram na primavera e no verão e os menores no outono e no inverno, resultado este que também pode estar relacionado aos períodos de maior (verão) e menor (inverno) cobertura vegetal, ou seja, relacionando com o estágio fenológico das plantas.

A temperatura do ar (Figura 2) foi menor no interior da floresta em todas as estações do ano. Este resultado também foi obtido por Renaud et al. (2011) em um estudo sobre as condições microclimáticas em diferentes formações vegetais. Isso mostra a importância da cobertura do dossel durante as horas mais quentes do dia e a redução na perda de água por evaporação. Os maiores valores médios de temperatura ocorreram no verão, sendo que a média diária na floresta foi de $16,80^{\circ} \mathrm{C}$, com uma temperatura máxima de $25,59^{\circ} \mathrm{C}$ e mínima de $4,03^{\circ} \mathrm{C}$ e para a área aberta uma média diária de $18,32^{\circ} \mathrm{C}$, com máxima de $28,30^{\circ} \mathrm{C}$ e mínima de $3,61^{\circ} \mathrm{C}$. O resultado mostrou que houve diferença estatística entre os dois ambientes. As temperaturas mais baixas no interior da floresta ocorrem em função da interceptação da radiação solar pelo dossel vegetativo, no qual não permite aos raios solares atingirem as camadas internas. A variação da temperatura também foi reduzida no interior da floresta $( \pm 2,82)$ tendo em vista a área aberta $( \pm 3,12)$. Isso mostra que a cobertura florestal é uma espécie de tampão, sendo que na floresta não há circulação significativa de ventos e variação abrupta de temperatura do ar. Segundo Renaud e Rebetez (2009), quanto mais quente for a temperatura do ar, maior é o impacto da floresta sobre esta variável. Além disso, a retirada das florestas e a implantação de pastagem ocasionam consequências na hidrologia de bacias hidrográficas, sobretudo na disponibilidade de água (SALEMI et al., 2012).

A velocidade do vento foi marcada por altos índices no verão em área aberta, como mostra a Figura 2. Na parte interna da floresta houve pouca diferença, sendo que seu comportamento foi homogêneo durante todas as estações do ano, demonstrando que ventos e brisas são bloqueadas pelos troncos e folhas do dossel, não chegando a atingir o interior do fragmento florestal. A velocidade no interior da floresta foi reduzida em $87,9 \%$ considerando aquela da parte externa. Rossetti, Pellegrino e Tavares (2010) mencionaram em seu estudo que, em áreas com vegetação densa, a velocidade do vento pode ser reduzida em até $85 \%$. De acordo com Martins, Guarnieri e Pereira (2008), o vento é gerado pela diferença do gradiente de pressão, provocado pela baixa umidade do ar e pelas altas temperaturas. Considerando a variação dos dados, houve variação de $0,01 \%$ na parte interna e de $6,74 \%$ na parte externa, deixando claro a ação do dossel vegetativo na atenuação das rajadas de vento. Neste estudo a velocidade máxima registrada foi de $11,38 \mathrm{~m} . \mathrm{s}^{-1}$ no mês de janeiro de 2013 na parte externa.

A evapotranspiração (Figura 2) apresentou diferença significativa entre as estações do ano (Tabela 1), sendo que a área aberta (pastagem) devolveu $77,3 \%$ do volume precipitado no ano, na forma de vapor. A parte interna da floresta, por outro lado, devolveu apenas $14,3 \%$ do total precipitado. Por meio da regressão linear $(y=1.602 \mathrm{x}+14.972)$ estimou-se que as precipitações inferiores a $9,4 \mathrm{~mm}$ são totalmente interceptadas pelo dossel da floresta e evaporadas diretamente para a atmosfera, não chegando a atingir o solo. Este resultado é superior aos valores encontrados por Ávila et al. (2014), que afirmaram que em regiões de Mata Atlântica as chuvas inferiores a 1,58 $\mathrm{mm}$ são totalmente interceptadas pelo dossel da floresta e retornadas para a atmosfera por meio da evaporação. Valor semelhante foi enfatizado por Moura et al. (2009), em que precipitações inferiores a $3,45 \mathrm{~mm}$ eram totalmente interceptadas pelo dossel vegetativo e devolvidas para a atmosfera pelo processo de evaporação. Não devolver água para a atmosfera por meio da evapotranspiração indica maior disponibilidade hídrica e mais água disponível no solo para as plantas e animais. A evapotranspiração em área aberta estimada por Penman-Monteith foi maior durante o período de primavera/verão $(532,68$ - 583,60 mm) e o menor no período de outono/inverno 
(400,04 - 356,34 mm). Este resultado é atribuído em vista que o cálculo de evapotranspiração por Penman-Monteith é dependente principalmente dos valores de radiação, temperatura e vento. $\mathrm{Na}$ parte interna, os maiores valores de evapotranspiração ocorreram na primavera com 68,60 $\mathrm{mm}$ e no verão com $52,68 \mathrm{~mm}$ e os menores no outono com $40,38 \mathrm{~mm}$ e no inverno com 42,66 $\mathrm{mm}$. Matsumoto et al. (2008) também encontraram os maiores valores de evapotranspiração no verão (julho/agosto) em florestas de clima temperado em Hokkaido, Japão. De acordo com Devine e Harrington (2007), normalmente solos sem cobertura vegetal possuem maiores taxas de evaporação, haja vista que a cobertura vegetal proporciona redução nas temperaturas do solo e do ar. Segundo Andrade et al. (2014), o dossel vegetativo das florestas protege o solo da incidência da radiação solar, ventos e controle da temperatura.

$\mathrm{O}$ interior da floresta apresentou os menores valores de temperatura do solo (Figura 2) comparado a área aberta com presença de pastagem. Em média a temperatura diária do solo na área aberta foi de $19,47^{\circ} \mathrm{C}$ e no interior da floresta de $16,90^{\circ} \mathrm{C}$, o que representa uma redução de $2,5^{\circ} \mathrm{C}(13,20 \%)$. Este resultado também foi confirmado por Falcão et al. (2010), que atribuíram os maiores valores de temperatura do solo a maior retenção da radiação solar, pois em áreas com vegetação o dossel possui a capacidade de refletir ou absorver grande parte da radiação solar incidente. $\mathrm{O}$ autor encontrou menores valores de temperatura do solo para o interior da floresta no qual foram reduzidas em $5,4^{\circ} \mathrm{C}$, tendo o maior impacto sobre as temperaturas máximas. A redução na temperatura do solo pode ser explicada pelo fato de que no interior da floresta o solo recebe menos radiação solar e com isso ocorre um menor fluxo de calor e consequentemente uma redução na temperatura do solo. Outro ponto a ser destacado foi a menor variação da temperatura do solo na parte interna da floresta, com uma variação de $2,5 \%$ para o interior e de 3,6\% para a parte externa. A temperatura do solo tem papel essencial sobre processos biogeoquímicos (WAGLE; KAKANI, 2014). Diante disso, pode-se dizer que em áreas de florestas, os processos de ciclagem de nutrientes tendem a ser mais lentos, o que proporciona maior acúmulo de matéria orgânica na parte superficial do solo.

A avaliação da variação climática e a amplitude diária que ocorrem ao longo do dia, foram avaliadas em quatro horários ( $3 \mathrm{~h}, 9 \mathrm{~h}, 15 \mathrm{~h}$ e $21 \mathrm{~h}$ ) (Tabela 2). A temperatura do ar, velocidade do vento, radiação e temperatura do solo apresentaram valores mais elevados na área de pastagem, e maiores oscilações durante o dia como observado no desvio padrão. As maiores diferenças ocorrem às $15 \mathrm{~h}$, sendo que os valores à noite são muito próximos e passam a aumentar a partir das $9 \mathrm{~h}$. A temperatura do ar apresentou padrões bem semelhantes para ambas as estações, com valores baixos durante a noite, aumentando durante o dia, atingindo valores máximos às $15 \mathrm{~h}$. De acordo com Flerchinger et al. (2015) e Salazar et al. (2015), as florestas tropicais mantêm a temperatura do ar mais baixa em relação à área aberta e reduz os fluxos de calor latente e sensível à noite. A velocidade do vento não sofreu impacto no interior da floresta. Na parte externa, no entanto, a velocidade do vento apresentou variação diária inferiores ao amanhecer, aumentando gradativamente durante o dia com pico máximo às $15 \mathrm{~h}$ da tarde.

O comportamento diário mostrou que os menores valores de radiação ocorreram no período noturno, aumentando acentuadamente ao amanhecer e com valores máximos no período da tarde. Segundo Gomes et al. (2015), ao amanhecer (6h) com a incidência da radiação solar, o saldo de radiação passa a ser governada pelo balanço de ondas curtas, fazendo com que este aumente até atingir valores máximos próximos do meio-dia. À tarde (13h), o saldo de radiação descresse significativamente, podendo alcançar valores negativos durante a noite.

A temperatura média do solo teve seu valor mínimo durante a noite e, em seguida, aumentou durante o dia até o seu valor máximo às 15h. Segundo Bonan (2008), as copas das árvores com alto índice de área foliar promovem a interceptação de $95 \%$ da luz visível que atinge o solo e assim proporciona condições de menores temperaturas durante o dia. Este resultado mostra que solos desprotegidos apresentam variações significativas no fluxo de calor do solo, com valores elevados durante o dia e amenos durante a noite. A diferença entre a temperatura do solo e do ar na superfície do solo é resultado dos processos de troca de calor do solo com a atmosfera 
(CARNEIRO et al., 2013). Alguns autores, como Prevedello (2010), relatam menores amplitudes térmicas próximo à superfície do solo em áreas cobertas, enquanto na atmosfera, a amplitude é relativamente alta. Isso pode ser explicado pelo fato de as trocas de calor no solo ocorrerem por condução, que é lento. A transferência de calor na atmosfera ocorre por convecção, que é um processo rápido de remoção do ar quente para as camadas superiores durante o dia e impedir o aquecimento excessivo do ar próximo à superfície. Belan et al. (2013), também relataram a ocorrência de menores amplitudes térmicas ao longo do dia em condições de cobertura vegetal.

Tabela 2 - Análise estatística das variáveis climáticas em diferentes horas do dia para a área aberta (pastagem) e floresta.

Table 2 - Statistical analysis of climatic variables at different hours of the day for the open area (grassland) and forest.

\begin{tabular}{|c|c|c|c|c|c|c|c|c|c|c|c|c|c|}
\hline \multirow{3}{*}{$\begin{array}{l}\text { Variáveis } \\
\begin{array}{l}\text { Umidade } \\
\text { relativa (\%) }\end{array}\end{array}$} & \multirow{2}{*}{$\frac{\text { Local }}{\text { Externo }}$} & \multicolumn{3}{|c|}{$3 \mathrm{~h}$} & \multicolumn{3}{|c|}{$9 \mathrm{~h}$} & \multicolumn{3}{|c|}{$15 \mathrm{~h}$} & \multicolumn{3}{|c|}{$21 \mathrm{~h}$} \\
\hline & & 98,61 & \pm & 0,98 & 94,81 & \pm & 2,06 & 80,04 & \pm & 2,54 & 96,39 & \pm & 1,45 \\
\hline & Interno & 97,13 & \pm & 4,41 & 96,84 & \pm & 4,22 & 85,21 & \pm & 4,25 & 96,39 & \pm & 3,30 \\
\hline \multirow{2}{*}{$\begin{array}{l}\text { Temperatura } \\
\left({ }^{\circ} \mathrm{C}\right)\end{array}$} & Externo & 16,31 & \pm & 2,91 & 18,16 & \pm & 3,78 & 22,62 & \pm & 3,60 & 17,80 & \pm & 2,91 \\
\hline & Interno & 15,45 & \pm & 2,57 & 16,02 & \pm & 2,93 & 19,74 & \pm & 3,22 & 16,43 & \pm & 2,67 \\
\hline \multirow{2}{*}{$\begin{array}{l}\text { Velocidade do } \\
\text { vento }\left(\mathbf{m} \cdot \mathbf{s}^{-1}\right)\end{array}$} & Externo & 2,46 & \pm & 1,19 & 2,82 & \pm & 1,19 & 4,16 & \pm & 1,86 & 3,59 & \pm & 2,18 \\
\hline & Interno & 0,36 & \pm & 0,05 & 0,39 & \pm & 0,05 & 0,42 & \pm & 0,05 & 0,39 & \pm & 0,07 \\
\hline \multirow{2}{*}{$\begin{array}{l}\text { Radiação } \\
\left(\text { MJ.m }{ }^{-2} \cdot \text { dia }\right)\end{array}$} & Externo & 0,13 & \pm & 0,05 & 346,29 & \pm & 121,89 & 394,16 & \pm & 98,09 & 1,73 & \pm & 2,58 \\
\hline & Interno & 1,74 & \pm & 0,26 & 31,52 & \pm & 5,30 & 53,20 & \pm & 15,89 & 1,66 & \pm & 0,23 \\
\hline \multirow{2}{*}{$\begin{array}{l}\text { Temperatura } \\
\text { do solo }\left({ }^{\circ} \mathbf{C}\right)\end{array}$} & Externo & 18,72 & \pm & 3,65 & 19,57 & \pm & 4,03 & 21,97 & \pm & 4,11 & 19,55 & \pm & 3,83 \\
\hline & Interno & 16,54 & \pm & 2,62 & 16,33 & \pm & 2,64 & 17,34 & \pm & 2,72 & 17,04 & \pm & 2,70 \\
\hline
\end{tabular}

O comportamento da umidade relativa do ar em função do horário demonstra uma relação inversa entre os ambientes. Durante a noite, os valores são próximos e com pouca variação, porém, durante o dia os maiores valores ficam restritos à área interna a floresta, considerando que os valores aumentam a partir do amanhecer chegando a ter $5 \%$ mais umidade às $15 \mathrm{~h}$. Este resultado confirma definitivamente que as florestas têm uma umidade relativa maior do que o ar em áreas abertas, ou seja, ambiente mais quente tem uma umidade relativa menor que o ambiente mais frio. Além das condições de menor temperatura, a transpiração realizada pelas plantas e a retenção da umidade proporcionada pelo dossel vegetativo devem ser considerados como contribuinte do aumento da umidade relativa no interior da floresta.

\section{Conclusão}

Este trabalho demonstrou a importância dos remanescentes florestais da floresta ombrófila densa pertencentes ao bioma Mata Atlântica na atenuação das variáveis meteorológicas locais. Através dos resultados foi observado que os serviços ecossistêmicos de regulação da floresta formam o microclima especifico em seu interior, que é essencial para a biodiversidade local. A atenuação das variáveis durante situações extremas, como o período de verão, reduziu a radiação global em $89,9 \%$, a evapotranspiração em $90,9 \%$ e a velocidade do vento em $94,1 \%$. Outro fato importante, foi a interceptação da precipitação pelo dossel com $41,2 \%$ do volume total de água precipitado na parte externa, mostrando a capacidade de armazenamento de água pelas folhas, caules e troncos. 
O comportamento ao longo do dia das variáveis microclimáticas também corroborou a função de regulação, com valores mais elevados nas áreas abertas e próximo das $15 \mathrm{~h}$, e valores mais baixos nos ambientes florestais e durante a noite. Para a umidade relativa do ar, o comportamento foi inverso, em virtude do aquecimento das massas de ar pela radiação global. Vale ressaltar que a falta de estudos teórico-científicos no bioma Mata Atlântica limita a comparação com outros estudos, já que este bioma possui características específicas. Contudo, os resultados alcançados são de extrema importância para gerar conhecimento sobre o ambienta local e embasar novos trabalhos sobre a influência das mudanças de uso da terra sobre as condições microclimáticas das florestas do bioma Mata Atlântica.

Como sugestão, comitês ou órgãos de bacias hidrográficas deveriam realizar o monitoramento de um número mais elevado de bacias hidrográficas e de diferentes gradientes de ocupação, no sentido de determinar de forma mais adequada a localização de áreas de preservação/ conservação dos fragmentos florestais e selecionar as áreas de uso agrícolas, no sentido de regular/equilibrar seu uso e assim aprimorar os processos hidrológicos e consequentemente o funcionamento qualitativo e quantitativo da bacia.

\section{Agradecimentos}

Os autores agradecem o apoio da Coordenação de Aperfeiçoamento de Pessoal de Nível Superior (Capes) - CAPES pela concessão de recursos para o projeto e pelas bolsas de estudo para primeiro, quarto e quinto autores.

\section{Referências}

ALMEIDA, D. S. Recuperação ambiental da Mata Atlântica. $3^{\text {rd }}$ ed. rev. Ilhéus: Editus, 2016, 200 p.

ALVES, R. F. et al. Avaliação da precipitação efetiva de um fragmento de Mata Atlântica em diferentes estágios de regeneração no município de Viçosa, MG. Ambi-Água, Taubaté, v. 2, n. 1, p. 83-93, 2007.

ANDRADE, A. M. D. et al. Radiação fotossinteticamente ativa incidente e refletida acima e abaixo do dossel de floresta de mata atlântica em Coruripe, Alagoas. Revista Brasileira de Meteorologia, São Paulo, v. 29, n. 1, p. 68-79, 2014.

ARRUDA, K. E. C. Estudo da amenidade térmica proporcionada pela Reserva Ecológica de Dois Irmãos, Recife-PE. Revista Brasileira de Geografia Física, Recife, v. 3, n. 3, p. 196-203, 2011.

ARTAXO, P. et al. Perspectivas de pesquisas na relação entre clima e o funcionamento da floresta Amazônica. Ciência e Cultura, São Paulo, v. 66, n. 3, 2014.

AMERICAN SOCIETY OF CIVIL ENGINEERS; ENVIRONMENTAL \& WATER RESOURCES INSTITUTE. The ASCE Standardized reference evapotranspiration equation. Report of the task committee on standardization of reference evapotranspiration. [S. l.], 2005.

ASHCROFT, M. B.; GOLLAN, J. R. Fine-resolution $(25 \mathrm{~m})$ topoclimatic grids of near-surface $(5$ $\mathrm{cm})$ extreme temperatures and humidities across various habitats in a large $(200 \times 300 \mathrm{~km})$ and diverse region. International Journal of Climatology, Chichester, n. 32, p. 2134-2148, 2012.

ÁVILA, L. F. et al. Partição da precipitação pluvial em uma microbacia hidrográfica ocupada por Mata Atlântica na serra da Mantiqueira, MG. Ciência Florestal, Santa Maria, v. 24, n. 3, p. 583$595,2014$.

BAKER, T. P. et al. Microclimate trough space and time: Microclimate variation at the edge regeneration forest ever daily, yearly and decadal time scale. Forest Ecology Management, [s. l.], v. 334, p. 174-184, 2014. 
BELAN, L. L. et al. Dinâmica entre temperaturas do ar e do solo sob duas condições de cobertura. Revista Acadêmica, Ciência Animal, Curitiba, v. 11, supl 1, p. S147-S154, 2013.

BONAN, G. Ecological climatology. 2 $2^{\text {ed }}$ Cambridge: Cambridge University Press, 2008.

CARNEIRO, R. G. et al. Fluxo de calor do solo e saldo de radiação dentro de uma área de Mata Atlântica em comparação com uma área de Cana-de-açúcar. Revista Brasileira de Geografia Física, Pernambuco, v. 6, n. 3, p. 555-565, 2013.

CARNEIRO, R. G. et al. Variabilidade da temperatura do solo em função da liteira em fragmento remanescente de mata atlântica, Revista Brasileira de Engenharia Agrícola e Ambiental, Campina Grande, v. 18, n. 1, p. 99-108, 2014.

CUARTAS L. A. et al. Interception water-partitioning dynamics for a pristine rainforest in Central Amazonia: marked differences between normal and dry years. Agricultural and Forest Meteorologyis, [s. l.], v. 145, p. 69-83, 2007.

DEVINE, W. D.; HARRINGTON, C. A. Influence of harvest residues and vegetation on microsite soil and air temperatures in a young conifer plantation. Agricultural and Forest Meteorology, [s. l.], v. 145, n. 1, p. 125-138, 2007.

FALCÃO, R. et al. Análise da variação da umidade relativa do ar do Pico da Bandeira, Parque Nacional Alto Caparaó, Brasil. In: SEMINÁRIO IBERO-AMERICANO DE GEOGRAFIA FÍSICA, 2., 2010, Coimbra. Anais [...] Coimbra: Universidade de Coimbra, 2010.

FLERCHINGER, G. N. et al. Modeling temperature and humidity profiles within forest canopies. Agricultural and Forest Meteorology, [s. l.], v. 213, p. 251-262, 2015.

FREITAS, J. P. O. et al. Distribuição da água de chuva em Mata Atlântica. Ambi-Água, Taubaté, v. 8, n. 2, p. 100-108, 2013.

GOMES, J. B. et al. Conversão de florestas tropicais em sistemas pecuários na Amazônia: quais as implicações no microclima da região? Revista Brasileira de Climatologia, Curitiba, v. 17, p. 2237-8642, 2015.

GOTARDO, R. et al. Distribuição espacial e temporal das chuvas no estado de Santa Catarina. Geosul, Florianópolis, v. 33, n. 67, p. 253-276, 2018.

HARDWICK, S. R. et al. The relationship between leaf area index and microclimate in tropical forest and oil palm plantation: Forest disturbance drives changes in microclimate. Agricultural and Forest Meteorology, [s. l.], v. 201, p. 187-195, 2015.

MAHMOUD, A. H. A. Analysis of the microclimatic and human comfort conditions in an urban park in hot and arid regions. Building and Environment, Oxford, n. 46, p. 2641-2656, 2011.

MAKARIEVA, A.; GORSHKOV, V.; LI, B. Revisiting forest impact on atmospheric water vapor transport and precipitation. Theoretical and Applied Climatology, Wien, v. 111, p. 79-96, 2013.

MARTINS, F. R.; GUARNIERI, R. A.; PEREIRA, E. B. O aproveitamento da energia eólica. Revista Brasileira de Ensino de Física, São Paulo, v. 30, n. 1, p. 1304, 2008.

MATSUMOTO, K. et al. Responses of surface conductance to forest environments in the Far East. Agricultural and Forest Meteorology, Amsterdam, v. 148, p. 1926-1940, 2008.

MENDONÇA, F; DANNI-OLIVEIRA, I. M. Climatologia: noções básicas e climas do Brasil. São Paulo: Oficina de Textos, 2007.

MOOJEN, T. M. B.; CAVALCANTE, R. B. L.; MENDES, C. A. Avaliação da radiação solar com base em dados de nebulosidade. Geografia, Londrina, v. 21, n. 3, p. 41-55, 2012.

MOURA, A. E. S. S. et al. Interceptação das chuvas em um fragmento de floresta da Mata Atlântica 
na Bacia do Prata, Recife, PE. Revista Árvore, Viçosa, MG, v. 33, n. 3, p. 461-469, 2009.

ORGANIZAÇÃO METEOROLÓGICA MUNDIAL. Guide to Meteorological Instruments and Methods of Observation. $7^{\text {th }}$ ed. Geneva: Secretariat of the World Meteorological Organization, 2008.

PREVEDELLO, C. L. Energia térmica do solo, In: VAN LIER, Q. J. (ed.). Física do solo. Viçosa, MG: Sociedade Brasileira de Ciência do Solo, 2010. 298 p.

RENAUD, V. et al. Comparison between open-site and below-canopy climatic conditions in Switzerland for different types of forests over 10 years (1998-2007). Theoretical and Applied Climatology, Wien, v. 105, p. 119-127, 2011.

RENAUD, V.; REBETEZ M. Comparison between open-site and below-canopy climatic conditions in Switzerland during the exceptionally hot summer of 2003. Agricultural and Forest Meteorology, Amsterdam, v. 149, n. 5, p. 873-880, 2009.

ROSSETTI, A. I. N.; PELlEGRINO, P. R. N.; TAVARES, A. R. As árvores e suas interfaces no ambiente urbano. REVSBAU, Piracicaba, v. 5, n. 1, p. 1-24, 2010.

SALAZAR, A. et al. Land use and land cover change impacts on the regional climate of non-Amazonian South America: A review. Global and Planetary Change, Amsterdam, v. 128, p. 103-119, 2015.

SALEMI, L. F. et al. Consequências hidrológicas da mudança de uso da terra de floresta para pastagem na região da Floresta tropical pluvial atlântica, Revista Ambiente \& Água, Taubaté, v. 7, n. 3, p. 127-140, 2012.

SANTOS, R. A. G. et al. Avaliação e caracterização da temperatura do solo em relação ao saldo de radiação dentro de uma floresta de Mata Atlântica em Coruripe - Alagoas. Geografia Física, Pernambuco, n. 4, p. 923-936, 2012.

SILVA, M. F. A. et al. avaliação da temperatura do solo, temperatura do ar e umidade relativa do ar em uma clareira de mata atlântica no município de São Cristóvão, Sergipe, Brasil. Agroforestalis News, Aracaju, v. 1, n. 1, 2016.

TASUMI, M.; ALLEN, R. G.; TREZZA, R. At-surface reflectance and albedo from satellite for operational calculation of land surface energy balance. Journal of hydrologic Engineering, Reston, v. 13, p. 51-63, 2008.

VENÂNCIO, D. L.; OLIVEIRA, P. C. de F. A floresta e o ciclo hidrológico: os modelos para estimativa de interceptação florestal da precipitação. Revista Científica Multidisciplinar Núcleo do Conhecimento, São Paulo, v. 1, p. 604-616, 2017.

VIBRANS, A. C. et al. Using satellite image-based maps and ground inventory data to estimate the remaining Brazilian Atlantic forest in Santa Catarina. Remote Sensing of Environment, New York, v. 130. p. 87-95 2013.

VON RANDOW, C. et al. Comparative measurements and seasonal variations in energy and carbon exchange over forest and pasture in South West Amazonia. Theoretical and Applied Climatology, Wien, v. 78, p. 5-26, 2004.

WAGLE, P.; KAKANI, V. G. Confounding effects of soil moisture on relationship between ecosystem respiration and soil temperature in switchgrass. BioEnergy Research, [s. l.], n. 7, p. 789-798, 2014. 